\title{
More than just a five-minute conversation: A case study in civic engagement from Germany
}

\section{Dominik Hierlemann}

It is Winston Churchill who is widely misattributed as saying that 'the best argument against democracy is a five-minute conversation with the average voter'. And yet, in a time when populist movements are gaining increasing support, undoubtedly some readers will find an element of truth to this misquote. As a matter of fact, politicians desperately need to have more than just a five-minute conversation with the average voter in order to strengthen and rejuvenate democracy. In fact, I will present a project from 2011 when two German foundations conducted a thorough conversation with more than 10,000 average voters: the so-called Citizens' Forum (Bertelsmann Stiftung and Heinz Nixdorf Stiftung. 2014).

To put this public participation project into perspective, I would like to begin with a brief reflection on how Germany is perceived from the outside. Probably 'not too bad' might be the short answer to such a question. Germany's economy under Chancellor Angela Merkel is thriving. Looking simply at statistics, the general level of trust in government is relatively high compared to other countries. But from the inside perspective, the picture is quite different. In fact, there is not much of a difference between Germany and most Western countries. 


\section{Recognising disjuncture}

Germany, like many other Western nations, is experiencing a growing gap between politicians and the electorate. People are dissatisfied with how political decisions are made and, although they are still interested in politics - this, to me, is the interesting point-they are no longer interested in political parties or the way politics works. Taking a more theoretical approach, it is possible to say that the politics of delivery is coming to an end. Until recently, the working mode has been as follows: citizens were there to provide votes, politicians delivered results and citizens were perceived as clients; now this circular logic has fundamentally changed.

One of the major catalysts of the emergence of new forms of public participation in Germany-or of deliberative democracy approaches as it is also referred to in the academic community-was widespread discontentment about the non-involvement in big infrastructure projects. The case of Stuttgart 21, where literally hundreds of thousands of people rallied against plans to build a new underground train station is exemplary. It was not simply a case of 'not in my backyard' (NIMBY) citizens that took to the streets, but something much bigger. Citizens were obviously dissatisfied with how the planning process of an infrastructure project was being conducted. Moreover, and more significantly, they felt a systemic exclusion of political processes with far-reaching results.

It was around this time the Bertelsmann Stiftung (Foundation) decided to develop a new approach to engage citizens in politics. There were already many methods out there, of course, and many were already being applied in Australia and New Zealand. So the foundation, with its partners, did not aim at developing a totally new and different approach but rather aimed to make sure that whatever method was chosen fit the current situation in Germany. But we were not revolutionaries: the ultimate goal was and still is to complement our representative democracy, not to develop a substitute.

The overall rationale for the project was: how can we reduce the gap between politics and citizens? This may not sound very ambitious, but I still believe it is the single most important issue when we talk about citizen engagement. How can we, if not eliminate the gap, then at least reduce it? How can we have more channels of communication between citizens and politicians? A critical point to make here is that many 
participation projects that are initiated by governmental bodies on all levels have the sole aim of generating acceptance for decisions that have already been made. Clearly, this leads to even more frustration.

In communicating with their citizens, politicians should ideally start from the point of saying 'yes'. However, most often their focus is different. They are often more concerned about communication styles, communication forms and all sorts of new social media instruments that help them to deliver their message more clearly. Their impetus is rather 'yes, how can we convince citizens?' They wish to communicate their message better, not engage with citizens in a different way.

\section{The Forum dynamics}

The Citizens' Forum took place in 2011. It was a nationwide public participation project, and one of our central aims was to strengthen the democratic skills of citizens, to awaken or to revitalise political interest.

Democracy, we thought, needed new venues. When I had a discussion a while ago with a German minister, he complained that while he was travelling throughout his constituency, he always seemed to be meeting the same people. We may well think that this minister was not going to the right places; however, it was equally true that it was always the same types of people who were engaged in the traditional forms of politics.

One way we combated this was by holding the Citizens' Forum in 25 different places and — even more importantly_participants were selected at random. So we had 10,000 participants; 400 in each region. They were invited by the Federal President who initiated the project at the timewhich, though attractive at the time, led to some problems I will explore shortly.

And although it has been, until this point, the biggest project of its kind in Germany, some perspective must be kept. I recently met a woman from a Chinese non-government organisation who is doing a public participation project in China. When I told her we had 10,000 participants, she said that would be a bus stop in China.

The Citizens' Forum consisted of three key features. First of all, participants were randomly selected. This is critically important, but it also consumes a lot of time-not to mention money. We considered it important that, 
through this approach, as many heterogeneous perspectives as possible flowed into the forum so as to avoid the scenario of the minister in Germany I mentioned who just met the usual suspects. In order to achieve that, we worked with a call centre: they randomly selected participants, telephoned them and said, 'we're calling you on behalf of the Federal President'. People were informed on the phone about the project and they had an opportunity to look up a website with more details.

Still, many people hung up straight away. Others were happy to stay on the line for a good chat but then said, 'well, you're talking about politics, I'll get you my husband'. But we wanted to make sure that we had different perspectives, so we had three criteria: gender, educational status and age-because while it was easy to find a middle-aged engineer, it was quite difficult to get in touch with a young woman from East Germany with a low level of education. We had to conduct many phone calls in order to get such demographics in our forum.

The next feature was that we had a combination of offline and online activities. We started with a one-day opening event, followed by an online discussion, and finally a closing event at the end of an eight-week period. This timeframe and structure was important, as it meant people got to know each other quite well at the forum. The discussion culture at the Citizens' Forum distinguished itself significantly from discussions on newspaper online forums or anything else you will find on the web. Participants showed respect to one another and behaved in a way that allowed others to easily and willingly join discussions.

People also became familiar with the process during the day and it suited different participation needs or individuals' strengths. For example, men tended to do well in our 'world cafés', a method where people changed tables in order to get to know different perspectives, but senior citizens and female participants became quite engaged in our online discussion. Although participants were online, they did not only discuss onlinethey worked online to try to put a common text together. And this was the focus of the forum: the way our website was organised ensured that, by the end of the project, participants would have produced a written program.

In other words, the Citizens' Forum was not just for the sake of discussion. There was a tangible result, a program at the end of the day. At the time in 2011, the topic of our forum was how we could foster social cohesion 
in our society. Participants had a choice of six different committees ranging from educational policy over immigration issues to future forms of democratic engagement. The main work of the forum took place in these committees. This way they were not engaging with 10,000 other citizens or even 400 other citizens. Instead, participants engaged within a group of 50 or 60 different citizens, because we believed this was the group size where you could still get to know each other well and where it would still be possible to work on a common text.

It was important to create a sense of community right from the start. And, as in real life, we needed a kind of dramatic structure of events: participants needed a warming-up phase so they had the opportunity to get to know the website and how the online forum worked before they engaged in a discussion in our online forum. Moreover, the events were organised in a kind of world café format so that participants could hear from different people and get to know different perspectives.

In our world café setting, a group of up to six people sat at a table, engaging in a discussion. We had so-called table hosts, people who stayed at the table and told new arrivals to the table what had happened so far. People moved around the room and, at the end of the day, they came up with different thoughts and ideas. The committees were separated by pinboards, where voting for ideas took place. In this way, the discussion was funnel-shaped: many ideas at the beginning and then, at the end of the day, just four bullet points, which were suggestions based on the ideas.

This was the starting point for the online discussion. Because it was our belief that you cannot start an online discussion with a blank page. And so our participants were given their event results as starting points for their discussion and work that they were doing online.

Let us now come to the online deliberation. What did the website look like? First of all, we believed it was important there be a personal component involved. For this reason, participants entered the discussion with their real name and a portrait; this way, they knew, amongst themselves, whether they had met or not. Through the use of a kind of social media component, we could make the experience more convenient and familiar to participants. Moreover, the online deliberation was facilitated by former participants of our pilot projects. 
We didn't pay facilitators. Ordinary citizens facilitated the whole online deliberation. It was also important that we did not interfere in terms of content. It was left up to the participants to determine the content. In doing so, I think we were quite unique, because often there is a certain degree of guidance there.

Nevertheless, I would say our approach was structured very well. Because we wanted to make sure that after six to eight weeks, ultimately, results were being delivered. While we did not interfere in terms of content, we made sure all participants walked away with their result. To help achieve this, participants had to complete certain tasks. Initially some of them did not like this; the older participants tended to say 'homework-that's twenty years ago'.

But we were adamant that certain tasks be completed. Some took just five minutes. We explained the importance of this to be retention: normally, when starting an online discussion, people became involved very quickly, they participated actively for a couple of days. After that, participation usually declined equally fast. So how could we make sure that the level of participation remained high throughout the entire project? The solution was to intervene at least structurally from time to time. Organisers needed to get in touch with participants from time to time. For example, in the middle of our forum we phoned participants and asked them how they were finding it, whether they wanted to participate a little more actively and so on.

In our experience, the elderly were often especially fascinated with the internet. This cuts to the issue of the digital divide. Because while participants in our project who did not have a computer could go to the library, if they were not digital natives we needed to ensure that they received adequate training. From the experience of the Citizens' Forum, this did not tend to be a problem: while the younger, more internet-savvy generation can be critical of the online forum setup, elder citizens are increasingly becoming quite engaged and accepting.

The outcomes of our project were ideas and proposals on a range of topics connected to the question of how more social cohesion in German society could be achieved. Participants urged for a common nationwide educational policy, delivered concrete proposals on how to facilitate the integration of refugees on the local level, and developed far-reaching ideas like a state-guaranteed basic income. All of these topics were debated 
in a closing event with the Federal President in the former German Bundestag and in subsequent meetings with high-ranking politicians in Berlin. But they were also discussed on the regional level. In every one of these 25 forums, we had closing events, and the results of our project were discussed with councillors, mayors and members of parliament. And it was up to them, of course, whether they wanted to institute the results of the project in policy.

So what were the results of the project? At the beginning, expectations were high: when the Federal President is involved, people raise their expectations. Never mind that the President of Germany is a figurehead with few powers: the average person thinks that because they received an invitation from the Federal President, results from the forum will be implemented.

This means we often had to temper expectations. We made sure that citizens were familiar with the relevant political processes and we ensured some sort of procedural justice. What we told participants right from the beginning was that while we could not guarantee that any results of the projects would be implemented, we would make sure that participants had the chance and the opportunity to discuss results with relevant politicians.

\section{The findings}

Let me briefly share some insights I gained during this project. First of all, was online becoming the new normal? We conducted this project in 2011, when politicians were emphasising getting their message across online; nowadays, the emphasis is more specifically on social media. And yet, while this may be so, I would say the Citizens' Forum demonstrated the continued, strong desire for face-to-face engagement.

Consequently, we needed to create a mixture of face-to-face engagement and online deliberation. This could be done through different participation opportunities. We also needed to ensure we did not simply reach out to the usual suspects. Sometimes their participation is appropriate: if a new infrastructure project is to be built, for example, all relevant stakeholders need to be invited. Our impetus at the time was to get people from all walks of life, and to do so we needed to look beyond merely the well-educated, eloquent middle class who usually engage with the policymaking process. 
This is not to say that such a process is all about peace, love and harmony, much as the stereotype of citizen engagement might imply this. Inevitably, some people will be disappointed with the results. Conflicts arise within groups. These must be dealt with. Most importantly, it is not possible to maintain control over the process as a whole-the precise reason why traditional policymakers are not very keen on the idea. But, on the other hand, this is the very thing that makes such a process so attractive.

Finally, I wish to end with one last insight: that there are of course different definitions of public or civic participation derived from different perspectives. For politicians, it is seen as a tool for more effective communication to improve their messaging. They merely want to get in touch with citizens in different ways but often try to involve them in direct decision-making processes. But when you speak with citizens, it becomes very clear that they want to be directly involved in decisionmaking. All organisers of public participation projects need to keep these different attitudes in mind. Organisers do not only need to bridge the gap between politicians and citizens; they first of all need to bridge the gap between the different expectations and the possible outcome of public participation projects.

\section{References}

Bertelsmann Stiftung and Heinz Nixdorf Stiftung. 2014. 'Citizens' Forum: Community Input and Discussion for Greater Impact'. Available from buerger-forum.info/download/BuergerForumA5_engl_2014_final.pdf 
This text is taken from Opening Government: Transparency and Engagement in the Information Age, edited by John Wanna and Sam Vincent, published 2018 by ANU Press, The Australian National University, Canberra, Australia.

doi.org/10.22459/OG.04.2018.09 